\title{
Alimentos alergênicos sob a perspectiva regulatória: uma revisão
}

\author{
Allergenic foods from a regulatory perspective: a review \\ Alimentos alergénicos desde una perspectiva regulatoria: una revisión
}

Recebido: 28/12/2020 | Revisado: 28/12/2020 | Aceito: 29/12/2020 | Publicado: 03/01/2021

\author{
Marina de Paula Penna e Palhares \\ ORCID: https://orcid.org/0000-0001-8527-4331 \\ Universidade Federal de Minas Gerais, Brasil \\ E-mail: marinappenna@gmail.com \\ Pedro Paulo Borges dos Santos \\ ORCID: https://orcid.org/0000-0002-4974-2166 \\ Universidade Federal da Paraíba, Brasil \\ E-mail: pedrosantosfarmacia@gmail.com \\ Ana Luiza Soares dos Santos \\ ORCID: https://orcid.org/0000-0002-0155-2419 \\ Universidade Federal de Minas Gerais, Brasil \\ E-mail: analuizasoares17@gmail.com \\ Cristiane Lúcia Goddard \\ ORCID: https://orcid.org/0000-0003-3825-0518 \\ Fundação Ezequiel Dias, Brasil \\ E-mail: cristiane.goddard@funed.mg.gov.br \\ Scheilla Vitorino Carvalho de Souza \\ ORCID: https://orcid.org/0000-0003-0256-3782 \\ Universidade Federal de Minas Gerais, Brasil \\ E-mail: scheilla@bromatologiaufmg.com.br
}

\begin{abstract}
Resumo
A alergia alimentar consiste em uma reação imuno mediada decorrente da ingestão de um alimento alergênico por um indivíduo sensível. Ela pode se manifestar de forma branda, com sintomas cutâneos e gastrointestinais, contudo pode levar a consequências graves como a anafilaxia. Como ainda não existe cura para a alergia alimentar e os tratamentos disponíveis não possuem segurança e eficácia suficientes, a restrição do consumo do alimento alergênico é a intervenção mais apropriada. Portanto, os indivíduos alérgicos dependem de informações apresentadas nos rótulos dos alimentos para escolher, de maneira segura, quais produtos consumir. Dessa forma, muitos países tornaram obrigatória a declaração dos principais alimentos causadores de alergia na rotulagem de produtos embalados. O presente trabalho traz uma análise dos aspectos regulatórios deste tema em diferentes países. Foi possível evidenciar a evolução dos requisitos regulamentares, embora diferenças substanciais sejam desfavoráveis ao comércio internacional e à segurança dos alimentos.
\end{abstract}

Palavras-chave: Alergia alimentar; Alimentos alergênicos; Rotulagem; Legislação.

\begin{abstract}
Food allergy is an immunoreaction resulted by the ingestion of allergenic food by sensitive persons. It can result in less severe symptoms, like gastrointestinal and skin manifestations, but also can lead to great health hazardous as anaphylaxis. Once there is no cure to food allergies yet and the treatments available are not safe and effective enough, allergen avoidance is the more appropriate intervention. Therefore, allergic individuals rely on labelling information to make safer choices regarding food consumption. Because of this, many countries decided to establish mandatory declaration of major allergenic food within the label of pre-package food products. This work presents an analysis of the regulatory aspects of this theme in different countries. It was possible to evidence the evolution of regulatory requirements, although substantial differences are unfavorable to international trade and food safety.
\end{abstract}

Keywords: Food allergy; Allergenic foods; Labeling; Legislation.

\section{Resumen}

La alergia alimentaria consiste en una reacción inmunomediada que resulta de la ingestión de un alimento alergénico por un individuo sensible. Puede manifestarse de forma leve, con síntomas cutáneos y gastrointestinales, sin embargo puede tener consecuencias graves como la anafilaxia. Como todavía no existe cura para la alergia alimentaria y los tratamientos disponibles no son lo suficientemente seguros y eficaces, restringir el consumo del alimento que provoca la alergia es la intervención más adecuada. Por lo tanto, las personas alérgicas dependen de la información presentada en las etiquetas de los alimentos para elegir, de manera segura, qué productos consumir. Como resultado, muchos países han obligado a declarar los principales alimentos que causan alergias en la etiqueta de los productos envasados. El presente trabajo presenta un análisis de los aspectos regulatorios de este tema en diferentes países. Se pudo 
evidenciar la evolución de los requisitos regulatorios, aunque las diferencias sustanciales son desfavorables para el comercio internacional y la seguridad alimentaria.

Palabras clave: Alergia alimentaria; Alimentos alergênicos; Etiquetado; Legislación.

\section{Introdução}

A alimentação é notoriamente fundamental à manutenção da vida, no entanto, a interação humana com os alimentos extrapola a ingestão de nutrientes, de forma que a alimentação diz respeito também a forma como alimentos são combinados e preparados, a características do modo de comer e às dimensões culturais e sociais das práticas alimentares (Brasil, 2014). Desta forma, hábitos alimentares, além de se relacionarem a questões de saúde, refletem aspectos culturais e sociais relevantes de diferentes sociedades e contextos históricos (Bernardo, 2006).

Define-se alergia alimentar como um efeito adverso à saúde decorrente de uma resposta imune específica, devido à exposição a um determinado alimento, a qual representa um problema emergente de saúde pública (Boyce et al., 2011; Sicherer et al., 2011; Sicherer \& Sampson, 2018). O aumento da prevalência das alergias alimentares tem caracterizado este efeito adverso como um importante desafio tanto para a indústria alimentícia e serviços de alimentação, quanto para os órgãos regulamentadores (Besler, 2001).

As alergias alimentares são doenças complexas e multifatorais (Asbai, 2018) e diversas teorias são postuladas para justificar o aumento de sua prevalência, incluindo predisposição genética e epigenética, período neonatal, tipo de parto ao nascimento, dieta da gestante e da nutriz, aleitamento materno exclusivo, idade da introdução da alimentação complementar, de alimentos sólidos e de alimentos alergênicos, composição da microbiota intestinal e "hipótese de privação microbiana" (Odijik et al., 2003; Haddeland et al., 2005; Brandtzaeg, 2010; Martino \& Prescott, 2010; Neu \& Rushing, 2011; Sicherer, 2011; Mcbride et al., 2012; Grimshaw et al., 2014).

Um aumento nas ocorrências de danos proporcionados pelas alergias alimentares também tem sido evidenciado em um cenário de crescimento do consumo de alimentos industrializados. O emprego de novos insumos e ingredientes, de novas tecnologias de produção, de aditivos e coadjuvantes tem sido cada vez mais comum na indústria de alimentos. Se por um lado estes avanços resultam em benefícios, tanto para o setor produtivo quanto para os consumidores, por outro ocorre um distanciamento entre o consumidor e as informações acerca do produto. Dessa forma, a crescente incidência deste tipo de reação indesejada pode estar relacionada à desinformação sobre a natureza dos produtos consumidos (Gendel, 2012; Marins et al., 2014).

A ingestão de um alimento alergênico por um indivíduo sensível pode desencadear alergia alimentar que, na maioria das vezes, envolve respostas imunológicas mediadas pela imunoglobulina E (IgE), com ocorrência de sintomas cutâneos, gastrointestinais, respiratórios e sistêmicos, havendo risco de vida, caso ocorra anafilaxia (Jackson, 2003).

Uma vez que os tratamentos disponíveis até o momento não apresentam efetividade desejável ou possuem limitações, a exclusão dos alimentos causadores de alergia da dieta dos indivíduos sensíveis é a melhor intervenção possível para evitar a ocorrência de reações alérgicas (Jones et al., 2014; Lanser et al., 2015). Para tanto, a informação a respeito da presença de alergênicos nos alimentos é crucial, sendo o rótulo uma importante ferramenta para o manejo da dieta de exclusão, no caso dos produtos embalados, de forma que muitos países regulamentaram a rotulagem dos alimentos alergênicos com o objetivo de proteger os consumidores sensíveis (Gendel, 2012; Brasil, 2017).

A rotulagem dos principais alimentos que causam alergias alimentares foi regulamentada no Brasil por meio Resolução da Diretoria Colegiada (RDC) $n^{\circ}$ 26, de dois de julho de 2015, da Agência Nacional de Vigilância Sanitária (ANVISA) (Brasil, 2015 a). O regulamento entrou em vigor um ano depois de sua publicação, no entanto, desafios ainda são enfrentados pelos setores envolvidos, muitos deles vivenciados em outros países onde a declaração de alergênicos também é regulamentada. 
Cumpre destacar que a presença de alérgenos em alimentos, provenientes de contaminação cruzada, pode ser considerada uma das principais dificuldades para a garantia da segurança destes produtos para os indivíduos alérgicos. Isso porque a quantidade mínima de alérgeno capaz de desencadear eventos indesejáveis, inclusive os de alta gravidade é variável e muitas vezes não pode ser mensurada, dependendo do alimento e da sensibilidade do indivíduo que o consome. A declaração da potencial ocorrência de alergênicos nesse caso, apesar de importante, pode gerar informações controversas ou ser utilizada pelos fabricantes como uma maneira de se resguardar frente às contaminações não esperadas quando respeitadas as Boas Práticas de Fabricação (BPF) (Allen et al., 2014).

O objetivo do presente trabalho foi tratar a temática da alergia alimentar, com enfoque nos aspectos regulamentares, traçando-se um paralelo entre as legislações de diferentes países.

\section{Desenvolvimento}

O presente trabalho é uma pesquisa documental, exploratória, de caráter qualitativo (Pereira et al., 2018), que envolveu, fundamentalmente, a análise da legislação nacional e internacional sobre rotulagem de alimentos alergênicos.

\subsection{Histórico da regulamentação mundial}

A rotulagem é definida pela ANVISA como o conjunto de informações contidas na embalagem de um alimento, ou seja, toda inscrição, legenda, imagem ou toda matéria descritiva ou gráfica, escrita, impressa, estampada, gravada, gravada em relevo ou litografada ou colada sobre a embalagem do alimento (Brasil, 2002). Segundo Marins et al. (2014), no contexto da produção, distribuição e consumo de alimentos, o rótulo constitui um canal de comunicação entre produtores e consumidores, no qual tais figuras sociais buscam o favorecimento de seus interesses. $\mathrm{O}$ autor discute o papel da rotulagem no exercício do direito à informação por parte dos cidadãos e, consequentemente, do direito à saúde, tendo em vista que a rotulagem constitui um instrumento para escolhas alimentares conscientes.

No contexto da alergia alimentar, o acesso às informações adequadas sobre a presença de alergênicos nos alimentos é primordial para a proteção da saúde dos indivíduos sensíveis, uma vez que a restrição dietética é a principal estratégia para prevenir o aparecimento das complicações clínicas. A rotulagem constitui, portanto, o principal meio de comunicação pelo qual os fabricantes podem informar os consumidores sobre a presença de alergênicos nos alimentos embalados, permitindo o gerenciamento do risco de manifestações clínicas adversas (Brasil, 2018).

A necessidade de proteção aos consumidores sensíveis por meio da declaração da lista de ingredientes em alimentos embalados é, há muitos anos, reconhecida por instituições regulamentadoras internacionais. Contudo, foi com a expansão mundial do uso de aditivos, nas décadas de 1980 e 1990, que a questão dos alergênicos em alimentos foi colocada em evidência, pois tais compostos poderiam estar presentes de forma não intencional ou "mascarados" nos produtos industrializados (Gendel, 2012). Assim, órgãos reguladores atuaram junto às indústrias para que os rótulos fornecessem informações claras e consistentes, assim como para que fossem adotados controles visando à prevenção da presença de alergênicos não declarados, de forma a proteger os consumidores alérgicos (Gendel, 2013). Na Figura 1, encontra-se apresentada uma linha do tempo com as principais ocorrências mundiais relacionadas à regulamentação da rotulagem de alimentos alergênicos. 
Figura 1. Linha do tempo dos principais marcos da regulamentação da rotulagem de alimentos alergênicos no mundo.

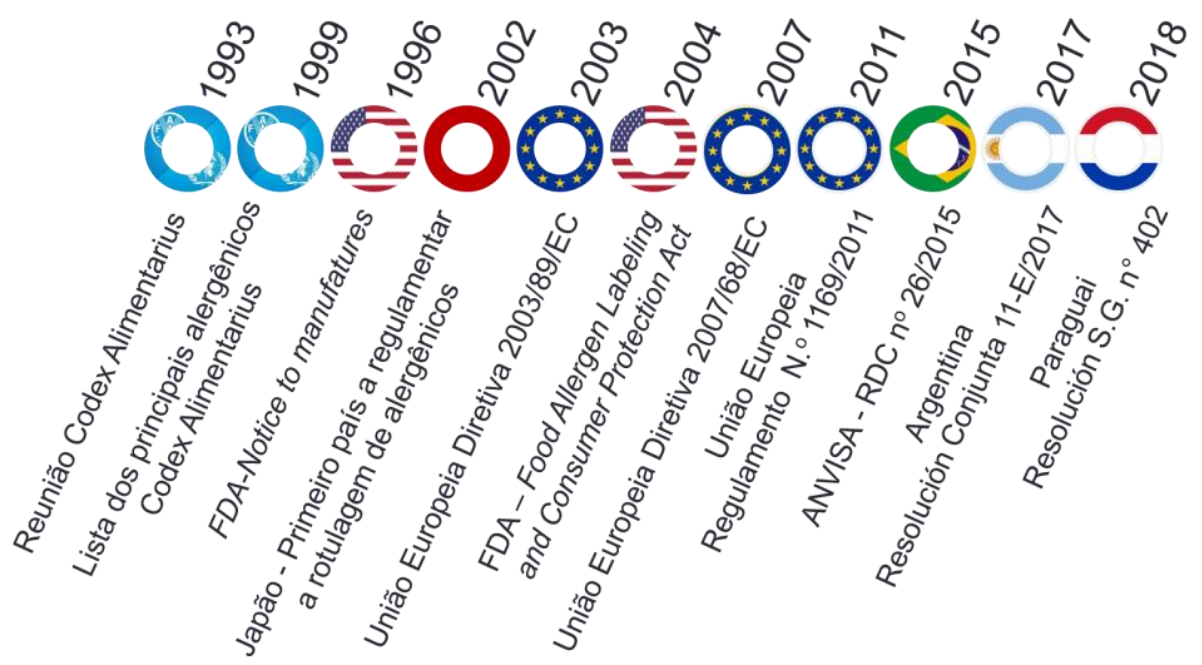

Fonte: Autores (com base em Codex Alimentarius, 1993; Fda, 1996; Codex Alimentarius, 2001; Fda, 2001; European Parliament, 2003; Fda, 2004; European Parliament, 2007; European Parliament, 2011; Gendel, 2012; Brasil, 2015 a; Argentina, 2017; República del Paraguay, 2018).

A rotulagem de alergênicos foi pauta da reunião do Comitê de Rotulagem de Alimentos do Codex Alimentarius (CCFL), em 1993, quando a delegação norueguesa apresentou um relatório sobre hipersensibilidade a alimentos. Na ocasião, foi tratada a necessidade de revisão da regra que instituía que os ingredientes correspondentes a menos de $25 \%$ da composição do alimento estavam isentos da declaração na lista de ingredientes. A discussão foi seguida de uma Consulta Técnica da Organização das Nações Unidas para a Alimentação e a Agricultura (FAO) e culminou na publicação, em 1999, de uma lista de alimentos a serem obrigatoriamente declarados (Codex Alimentarius, 1993; Codex Alimentarius, 2001; Gendel, 2012).

Em 1996, em decorrência de uma série de notificações de reações alérgicas a alimentos não declarados na rotulagem dos alimentos embalados, a agência regulatória americana, Food and Drug Administration (FDA), divulgou uma carta direcionada à indústria alimentícia pautando a importância da presença de informação sobre esses alimentos (Fda, 1996). Mais tarde, em 2001, a agência publicou uma declaração e um guia de inspeção com o propósito de reduzir a contaminação cruzada e melhorar a qualidade das informações contidas nos rótulos (Fda, 2001).

O Japão foi o primeiro país a regulamentar a rotulagem de alergênicos, em 2002, seguido da Austrália e Nova Zelândia. Após um ano, a União Europeia estabeleceu a Diretiva 2003/89/EC, que alterou a Diretiva 2000/13/EC, para incluir a obrigatoriedade da declaração de alimentos alergênicos, mesmo em concentrações mínimas, o que não era exigido anteriormente (European Parliament, 2003). A lista de alimentos alergênicos foi alterada pela Diretiva 2006/142/EC e, em seguida, pela Diretiva 2007/68/EC que detalhou as substâncias excetuadas (European Parliament, 2006; European Parliament, 2007). Nos Estados Unidos, a regulamentação oficial ocorreu em 2004, pelo Ato de Rotulagem de Alimentos em Proteção ao Consumidor (FALCPA) (Fda, 2004). Posteriormente, vários países regulamentaram a rotulagem de alergênicos, muitos deles baseados nas recomendações do Codex Alimentarius e da União Europeia (Gendel, 2012).

Frente à indicação de que a maior parte dos incidentes relacionados às alergias alimentares se dá pelo consumo de alimentos não embalados, na União Europeia, a obrigatoriedade de informações sobre alergênicos foi ampliada para esses produtos a partir da implementação do Regulamento (UE) n ${ }^{\circ}$ 1169/2011, que entrou em vigor no final de 2014. Por meio deste importante passo em relação à regulamentação internacional do tema, os estabelecimentos europeus nos quais são comercializados alimentos não embalados ou a granel, como cafés, restaurantes e supermercados, devem estar preparados para fornecer informações aos consumidores sobre os ingredientes e a presença de alergênicos, seja oralmente, quando requisitado, 
ou de forma escrita em menus, quadros e outros (European Parliament, 2011; Fsa, 2015).

No Brasil, os requisitos para rotulagem obrigatória dos principais alimentos que causam alergias foram regulamentados pela ANVISA, por meio da RDC nº 26/2015, que vigorou após um ano de sua publicação (Brasil, 2015 a). O processo foi resultado da mobilização de famílias de crianças com alergia alimentar que reivindicaram o direito à informação clara dos alergênicos na rotulagem. A legislação passou por consulta pública para a contribuição de membros da sociedade, comunidade científica e indústria, e contou com 3.531 participantes e 5.475 contribuições. Esta expressiva participação comprovou a importância do tema para os atores sociais envolvidos (Brasil, 2015 b).

A harmonização das regras para rotulagem de alergênicos entrou em discussão no bloco do Mercado Comum do Sul (Mercosul), porém o consenso entre os membros não foi alcançado (Mercosul, 2015 a; Mercosul, 2015 b). Após o Brasil, Argentina e Paraguai publicaram legislações próprias em 2017 e 2018, respectivamente (Argentina 2017, República del Paraguay, 2018). O Uruguai publicou consulta pública sobre o tema em 2020 (República Oriental del Uruguay, 2020).

Apesar de muitos países terem definido requisitos para a declaração de alergênicos nos rótulos de alimentos, existem diferenças fundamentais entre os regulamentos. No contexto da comercialização internacional, é interessante que exista uma harmonização das informações fornecidas pelos fabricantes de diferentes regiões, garantindo de fato a segurança dos consumidores (Gendel, 2012). Neste sentido, o tema voltou a ser pautado no Codex Alimentarius na $44^{\mathrm{a}}$ sessão do CCFL, em 2017, quando foi aprovada a elaboração de um documento de trabalho (Codex Alimentarius, 2018). O cronograma proposto prevê a aprovação das diretrizes em 2023 (Codex Alimentarius, 2019).

\subsubsection{Listas de alimentos alergênicos}

Embora existam relatos na literatura de mais de 170 alimentos causadores de alergia alimentar, estima-se que $90 \%$ dos casos sejam provocados por apenas oito desses alimentos. São eles: ovos, leite, peixe, crustáceos, castanhas, amendoim, trigo e soja (Brasil, 2017 a). Ademais, a dinâmica de desenvolvimento de novos produtos e ingredientes, com destaque para novas fontes alimentares, principalmente proteicas (Aiking \& Boer, 2020), que vêm sendo pesquisadas e desenvolvidas na tentativa de solucionar futuros problemas de segurança alimentar, que certamente impactará no cenário mundial das alergias alimentares.

As razões pelas quais alguns alimentos têm maior potencial alergênico que outros ainda não foram completamente elucidadas. Os alérgenos são majoritariamente proteínas ou glicoproteínas de peso molecular entre 10 e $70 \mathrm{kDa}$ que podem ter um ou mais epítopos. Cumpre destacar que um mesmo alimento pode conter vários alérgenos (Solé et al., 2008). Na Tabela 1, estão apresentados os principais alimentos alergênicos e as respectivas proteínas relevantes.

O processamento ou cozimento dos alimentos pode alterar o seu potencial alergênico, promovendo a diminuição da sua antigenicidade, no entanto, em outros casos tal alteração não ocorre de forma significativa, em função de alterações conformacionais de proteínas com exposição de epítopos anteriormente indisponíveis para sensibilização imunológica (Jackson, 2003). Dessa forma, ainda não há evidências suficientes para recomendação do consumo de produtos processados (Santos, 2016; Santos, 2017). 
Tabela 1. Composição proteica dos principais alimentos causadores de alergias alimentares.

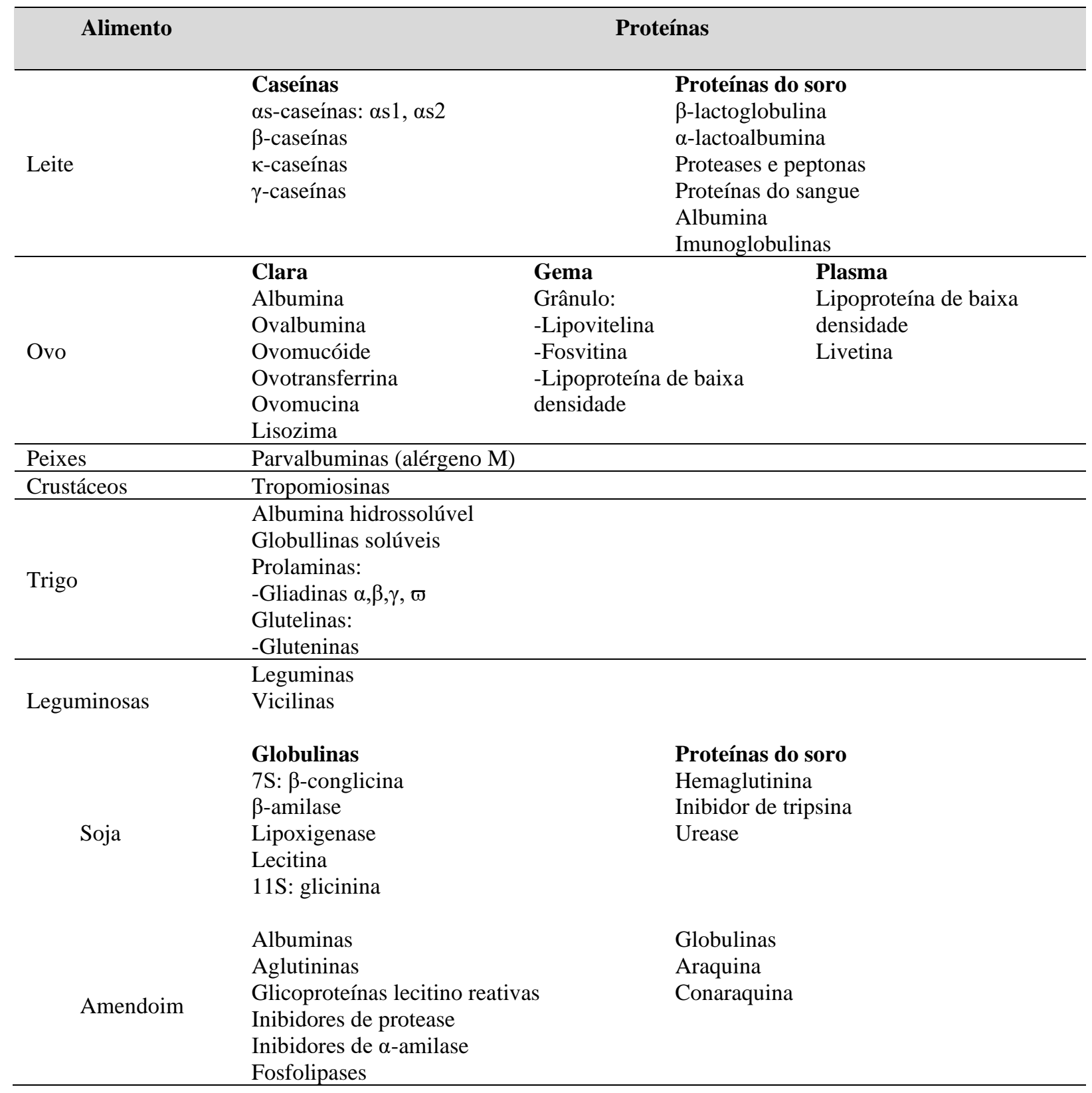

Fonte: Solé (2008, p 68), modificado.

Dentre as principais diferenças nos requisitos estabelecidos pelos diferentes países, podemos observar a lista de alimentos a serem declarados. Usualmente, são eleitos os principais alimentos ou aqueles responsáveis pela maior parte das alergias identificadas na população impactada pelo regulamento. Lee et al. (2008) demonstraram que perfis dietéticos diferentes entre países podem resultar em diferenças na alergenicidade a alimentos específicos, e discutiram possíveis interações com fatores ambientais. Tais autores alertaram para dificuldades inerentes em determinar a prevalência de alergia alimentar consistente em uma população. Em um estudo comparativo entre regulamentos internacionais, Gendel (2012) observou que a maioria das legislações declara os critérios de escolha da lista de alimentos alergênicos.

Os oito alimentos considerados os principais causadores de alergias estão presentes na maioria dos regulamentos. A adição de outros alimentos (Tabela 2) geralmente está relacionada aos hábitos alimentares característicos de cada população, além de outros critérios que são adotados para inclusão. 
Tabela 2. Principais alergênicos cuja declaração no rótulo é obrigatória em diferentes países.

\begin{tabular}{|c|c|c|c|c|c|c|c|c|c|}
\hline Alergênico & Codex & BR & $\mathbf{A R}$ & PY & $\mathbf{U E}$ & EUA & $\mathbf{C N}$ & $\mathrm{Au} / \mathrm{NZ}$ & $\mathbf{J P}$ \\
\hline Ovo & $\mathrm{x}$ & $\mathrm{x}$ & $\mathrm{x}$ & $\mathrm{x}$ & $\mathrm{x}$ & $\mathrm{x}$ & $\mathrm{x}$ & $\mathrm{x}$ & $\mathrm{x}$ \\
\hline Leite & $\mathrm{x}$ & $\mathrm{x}$ & $\mathrm{x}$ & $\mathrm{x}$ & $\mathrm{x}$ & $\mathrm{x}$ & $\mathrm{x}$ & $\mathrm{x}$ & $\mathrm{x}$ \\
\hline Peixe & $\mathrm{x}$ & $\mathrm{x}$ & $\mathrm{x}$ & $\mathrm{x}$ & $\mathrm{x}$ & $\mathrm{x}$ & $\mathrm{x}$ & $\mathrm{x}$ & \\
\hline Crustáceos & $\mathrm{X}$ & $\mathrm{x}$ & $\mathrm{x}$ & $\mathrm{x}$ & $\mathrm{x}$ & $\mathrm{x}$ & $\mathrm{x}$ & $\mathrm{x}^{3}$ & $\mathrm{x}$ \\
\hline Castanhas & $\mathrm{x}$ & $\mathrm{x}$ & $\mathrm{x}$ & $\mathrm{x}$ & $\mathrm{x}$ & $\mathrm{x}$ & $\mathrm{x}$ & $\mathrm{x}$ & \\
\hline Amendoim & $\mathrm{x}$ & $\mathrm{x}$ & $\mathrm{x}$ & $\mathrm{x}$ & $\mathrm{x}$ & $\mathrm{x}$ & $\mathrm{x}$ & $\mathrm{x}$ & $\mathrm{x}$ \\
\hline $\begin{array}{l}\text { Cereais que } \\
\text { contenham } \\
\text { glúten }\end{array}$ & $\mathrm{X}$ & $\mathrm{x}$ & $\mathrm{x}$ & $\mathrm{x}$ & $\mathrm{x}$ & $\mathrm{x}^{1}$ & $\mathrm{x}^{2}$ & $\mathrm{x}^{4}$ & $\mathrm{x}$ \\
\hline Soja & $\mathrm{x}$ & $\mathrm{x}$ & $\mathrm{x}$ & $\mathrm{x}$ & $\mathrm{x}$ & $\mathrm{x}$ & $\mathrm{x}$ & $\mathrm{x}$ & \\
\hline Gergelim & & & & & $\mathrm{x}$ & & $\mathrm{x}$ & $\mathrm{x}$ & \\
\hline Mostarda & & & & & $\mathrm{x}$ & & $\mathrm{x}$ & & \\
\hline $\begin{array}{l}\text { Mariscos/ } \\
\text { Moluscos }\end{array}$ & & & & & $\mathrm{x}$ & & $\mathrm{x}$ & & \\
\hline Aipo & & & & & $\mathrm{x}$ & & & & \\
\hline Tremoço & & & & & $\mathrm{x}$ & & & $\mathrm{x}$ & \\
\hline Sulfitos & & & $\mathrm{x}$ & & & & & $\mathrm{x}$ & \\
\hline Látex & & $\mathrm{x}$ & & & & & & & \\
\hline
\end{tabular}

BR: Brasil; AR: Argentina; PY: Paraguai; EU: União Europeia; EUA: Estados Unidos; CN: Canadá; Au/NZ: Austrália e Nova Zelândia; JP: Japão; 1:Trigo; 2: Trigo e triticale; 3: Camarão e caranguejo; 4: Trigo e trigo-sarraceno.

Fonte: Gendel, (2012); Brasil, (2015); Argentina, (2017); República del Paraguay, (2018).

No Brasil, os alimentos com obrigatoriedade de declaração são: trigo, centeio, cevada, aveia e suas estirpes hibridizadas; crustáceos; ovos; peixes; amendoim; soja; leites de todas as espécies de animais mamíferos; amêndoa (Prunus dulcis. sin.: Prinus amygdalus. Amygdalus communis L.); avelãs (Corylus sp.); castanha-de-caju (Anacardium occidentale); castanha-do-Brasil ou castanha-do-pará (Bertholletia excelsa); macadâmias (Macadamia spp.); nozes (Juglans spp.); pecãs (Carya spp.); pistaches (Pistacia spp.); pinoli (Pinus spp.); e castanhas (Castanea spp.); além do látex natural (Brasil, 2015 a).

Segundo a ANVISA, os alimentos incluídos foram os de maior relevância para a saúde pública, tendo como base os dados disponíveis sobre a prevalência e severidade das alergias alimentares, além do reconhecimento dos mesmos como principais alimentos alergênicos pelo Padrão Geral para Rotulagem de Alimentos Embalados do Codex Alimentarius. O látex natural, que já deveria ser obrigatoriamente declarado segundo a Lei nº 12.849/2013, foi incluído, uma vez que a substância e seus derivados podem estar presentes em materiais que entram em contato com alimentos, como luvas, embalagens e equipamentos e existem evidências de seu potencial alergênico. A legislação brasileira prevê a declaração voluntária de outros alimentos causadores de alergias alimentares, desde que sejam cumpridos os requisitos da norma (Brasil, 2017 a).

As espécies de origem do leite e ovos não foram explicitadas pelas listas de alimentos alergênicos dos regulamentos analisados por Gendel (2012). A ANVISA claramente determina a declaração de leite de todas as espécies animais e esclarece em material complementar que a declaração do nome comum dos leites deve ser composta pelo termo "LEITE" seguido da espécie animal, com exceção ao leite de vaca. (Brasil, 2015 a; Brasil, 2017 a). Todavia, não está claro se o mesmo procedimento é válido para ovos.

Além da variação dos alimentos a forma como eles são agrupados também é variável. As castanhas, por exemplo, são listadas individualmente e descriminadas pela espécie nas legislações brasileira e paraguaia (Brasil, 2015 a; República del Paraguay, 2018). No Codex Alimentarius, na Austrália e Nova Zelândia, elas são agrupadas pela designação culinária "tree nuts”, enquanto na legislação norte americana, são citados exemplos desta classificação. (Codex Alimentarius, 2001; Australia 
New Zealand Food Standards Code, 2011; Gendel, 2012). Segundo a ANVISA, a escolha por listar o grupo separadamente deve-se ao fato das castanhas não contemplarem um grupo taxonômico único, com grande variação na nomenclatura comum e científica desses alimentos. Assim, a apresentação dos nomes científicos na norma constituiu uma estratégia para elucidar as espécies abrangidas, mas a declaração na rotulagem fica restrita ao nome comum das castanhas (Brasil, 2017 a). O uso do termo culinário em detrimento da classificação botânica, segundo Gendel (2012), condiz com o objetivo de utilizar uma linguagem comum. A União Europeia e Canadá, apesar de agruparem as castanhas, delimitam oito e nove tipos de castanhas a serem declaradas, respectivamente (Gendel, 2012). A resolução argentina agrupa as castanhas, porém remete ao artigo específico do Código Alimentar Argentino que define oito grupos taxonômicos (Argentina, 2017).

O grupo dos cereais que contêm glúten é designado desta forma pelo Codex Alimentarius e nos regulamentos da União Europeia e da Austrália e Nova Zelândia, sendo que são nomeados os alimentos que fazem parte do grupo (Codex Alimentarius, 2001; Australia New Zealand Food Standards Code, 2011; European Parliament, 2011). As legislações brasileira, argentina e paraguaia, por sua vez, relacionam os alimentos (trigo, centeio, cevada e aveia), sem nomer o grupo (Brasil, 2015 a; Argentina, 2017; República del Paraguay, 2018). Nos Estados Unidos, a declaração é restrita ao trigo; no Canadá, ao trigo e triticale; e no Japão, declara-se trigo e trigo-sarraceno (Fda, 2004; Gendel, 2012).

Outros grupos como peixes e crustáceos também se diferem entre os regulamentos no que diz respeito à discriminação de espécies. A Coreia determina a declaração de apenas uma espécie de peixe. Quanto aos crustáceos, na Coreia, assim como no Japão, devem ser declarados apenas camarão e caranguejo. No Brasil, foi estabelecido que a declaração de crustáceos deve ser seguida do nome comum da espécie entre parênteses, por exemplo, “Alérgicos: Contém Crustáceos (lagosta)”. Medida semelhante foi adotada no Canadá, onde é exigido o uso do nome das espécies de crustáceos, peixes e mariscos; e também nos Estados Unidos, onde a declaração deve ser feita pelo "nome do tipo específico" para todos os grupos de alimentos alergênicos (Gendel, 2012; Brasil, 2015 a; Fda, 2004).

\subsubsection{Derivados de alimentos alergênicos}

Um dos aspectos mais importantes abordados pelos regulamentos é o tipo de linguagem utilizada para a declaração dos alimentos alergênicos, dado que, muitas vezes, a identificação desses produtos e seus derivados pode ser dificultada pela utilização de termos genéricos, técnicos ou científicos, por exemplo, “caseína" contrariamente a "leite". Por isso, alguns regulamentos indicam explicitamente a obrigatoriedade de declaração dos derivados de alergênicos. Os Estados Unidos e Canadá delimitam a declaração para os casos em que proteínas derivadas dos alimentos alergênicos estejam presentes no produto. O regulamento americano se refere aos "alimentos que contém proteínas derivadas de" um dos alimentos alergênicos, enquanto a expressão utilizada pela legislação canadense é “qualquer proteína derivada de" um alergênico. No Brasil, todos os derivados de alimentos alergênicos devem ser declarados com a utilização da expressão "contém derivados de" e o nome do alergênico de origem (Gendel, 2012; Brasil 2015 a).

Apesar disto, é possível que ingredientes, aditivos alimentares e coadjuvantes de tecnologia derivados de alimentos alergênicos sejam isentos da obrigatoriedade de declaração. Para tanto, é necessária a comprovação de que a substância em questão não configure um risco ao consumidor alérgico, mediante uma petição submetida à ANVISA. O Guia para Comprovação da Segurança de Alimentos e Ingredientes define quatro elementos que devem ser abordados na avaliação de risco: i) identificação do perigo; ii) caracterização do perigo; iii) avaliação de exposição; e iv) caracterização do risco (Brasil, 2015 a; Brasil, 2019).

Processos semelhantes são permitidos pelos regulamentos internacionais. Nos Estados Unidos, é possível requisitar a exclusão de ingredientes da obrigatoriedade de declaração como alergênico de duas maneiras, por meio de uma petição ou de uma notificação. A petição é utilizada para ingredientes que comprovadamente não provoquem respostas alérgicas 
representando risco à saúde humana. Já a notificação pode ser utilizada quando o ingrediente não possui a proteína alergênica ou quando comprovadamente não provoque respostas alérgicas (Gendel, 2013). Até o momento foram enviadas ao FDA cinco petições e oito notificações. Os alimentos submetidos à avaliação foram derivados de soja, leite, peixe e trigo. A maioria dos processos foi negada por falta de evidências suficientes para a isenção de declaração. Foi aceita uma notificação envolvendo uma proteína estruturante de gelo obtida por engenharia genética em Saccharomyces cerevisiae com genes de peixe (Macrozoaraces americanos). Uma petição para lecitina de soja foi aceita para o uso como agente de liberação na superfície de produtos, mas a necessidade de declaração foi mantida nos casos em que a substância for incorporada ao produto. Outra petição para lecitina de soja, desta vez usada como desmoldante foi avaliada positivamente pelo FDA (Fda, 2020 a; Fda, 2020 b).

\subsubsection{Apresentação da declaração}

Diferenças também são evidenciadas na forma de comunicação dos alimentos alergênicos nas regulamentações de diferentes países. A legislação brasileira estabelece, no Art. $8^{\circ}$, um padrão para a legibilidade e uniformidade da declaração de alergênicos. As advertências devem ser grafadas em caixa alta, negrito, ter cor contrastante com o fundo e altura mínima de dois milímetros (exceto para embalagens em que o painel principal tenha área inferior a cem centímetros quadrados) e estar localizadas imediatamente abaixo da lista de ingredientes. Curiosamente, essa informação é idêntica ao que trata o Art. $4^{\circ}$ da RDC n ${ }^{\circ}$ 136, de 08 de fevereiro de 2017, que "Estabelece os requisitos para declaração obrigatória da presença de lactose nos rótulos dos alimentos" e este fato resulta em dúvidas sobre qual declaração, de fato, deve estar imediatamente abaixo da lista de ingredientes. Contudo, não há um consenso sobre essa questão (Brasil, 2017 b). São previstos os seguintes dizeres: “Alérgicos: Contém (nomes comuns dos alimentos que causam alergias alimentares)”, “Alérgicos: Contém Derivados De (nomes comuns dos alimentos que causam alergias alimentares)" ou "Alérgicos: Contém (nomes comuns dos alimentos que causam alergias alimentares) E Derivados De (nomes comuns dos alimentos que causam alergias alimentares)”. A declaração "Alérgicos: Pode Conter (nomes comuns dos alimentos que causam alergias alimentares)" deve ser utilizada nos casos em que não for possível garantir a ausência de contaminação cruzada dos alimentos, ingredientes, aditivos alimentares ou coadjuvantes de tecnologia por alérgenos alimentares. Vale ressaltar que os alimentos destinados ao setor industrial ou serviços de alimentação podem fornecer a informação de alergênicos na documentação referente ao produto (Brasil, 2015 a).

Na Tabela 3 são apresentadas as principais diferenças em relação à localização, formatação e linguagem preconizadas pelo regulamento brasileiro e legislações internacionais.

Entre os regulamentos estudados por Gendel (2012), todos integraram a declaração de alergênicos à lista de ingredientes. No entanto, as legislações americana e canadense também definem o uso da expressão "CONTÉM" seguida dos alimentos alergênicos presentes no produto. A Diretiva 2003/89/EC da União Europeia determinava o uso da expressão “CONTÉM” sempre que os alergênicos não estavam claramente declarados na lista de ingredientes. Contudo, a legislação atual, Regulamento (UE) $n^{\circ}$ 1169/2011, preconiza a concentração das informações na lista de ingredientes (European Parliament, 2011).

Em um estudo qualitativo, Barnett et al. (2011) avaliaram as experiências e perspectivas em relação às escolhas de produtos alimentícios embalados de trinta e dois consumidores em restrição alimentar devido à alergia a castanhas. A maioria dos participantes demonstrou familiaridade com caixas de texto com a expressão "contém”, considerando-as uma fonte confiável de informações. Muitos informaram utilizar estas declarações em conjunto com a lista de ingredientes e alguns demonstraram maior confiança no conteúdo da lista. As caixas de texto foram mencionadas como estratégias úteis para padronização e localização rápida das informações sobre alergênicos. 
Tabela 3. Apresentação da declaração de alimentos alergênicos na rotulagem de alimentos de diferentes países.

\begin{tabular}{|c|c|c|c|}
\hline País & Localização & Formatação & Linguagem \\
\hline Brasil & $\begin{array}{l}\text { Imediatamente após ou } \\
\text { abaixo da lista de } \\
\text { ingredientes. }\end{array}$ & $\begin{array}{l}\text { Caixa alta, negrito, ter cor } \\
\text { contrastante com o fundo e } \\
\text { altura mínima de dois } \\
\text { milímetros. }\end{array}$ & $\begin{array}{l}\text { Nome comum do alimento } \\
\text { alergênico. } \\
\text { Advertências padronizadas: } \\
\text { "ALÉRGICOS: CONTÉM...", } \\
\text { "ALÉRGICOS: CONTÉM } \\
\text { DERIVADOS DE...", } \\
\text { "ALÉRGICOS: CONTÉM... E } \\
\text { DERIVADOS DE...", } \\
\text { "ALÉRGICOS: PODE } \\
\text { CONTER...". }\end{array}$ \\
\hline Argentina & $\begin{array}{l}\text { Imediatamente após ou } \\
\text { abaixo da lista de } \\
\text { ingredientes. }\end{array}$ & $\begin{array}{l}\text { Letra maiúscula, negrito, ter } \\
\text { cor contrastante com o fundo } \\
\text { e altura mínima de dois } \\
\text { milímetros, nunca inferior a } \\
\text { letra utilizada na lista de } \\
\text { ingredientes. }\end{array}$ & $\begin{array}{l}\text { Expressões: “CONTÉM...”, } \\
\text { "“CONTÉM DERIVADO/S } \\
\text { DE...", "CONTÉM... E } \\
\text { DERIVADO/S DE...", "PODE } \\
\text { CONTER...", "PODE } \\
\text { CONTER DERIVADOS } \\
\text { DE...", "PODE CONTER... E } \\
\text { DERIVADOS DE..." }\end{array}$ \\
\hline Paraguai & $\begin{array}{l}\text { Imediatamente após ou } \\
\text { abaixo da lista de } \\
\text { ingredientes. }\end{array}$ & $\begin{array}{l}\text { Letra maiúscula, negrito, ter } \\
\text { cor contrastante com o fundo } \\
\text { e altura mínima de dois } \\
\text { milímetros, nunca inferior a } \\
\text { letra utilizada na lista de } \\
\text { ingredientes. }\end{array}$ & $\begin{array}{l}\text { Expressões: “CONTÉM...”, } \\
\text { “CONTÉM DERIVADO } \\
\text { DE...”, "PODE CONTER..." }\end{array}$ \\
\hline União Europeia & $\mathrm{Na}$ lista de ingredientes. & $\begin{array}{l}\text { O nome do alimento } \\
\text { alergênico deve ser realçado } \\
\text { por uma grafia que a } \\
\text { distinga claramente do } \\
\text { restante da lista de } \\
\text { ingredientes. }\end{array}$ & $\begin{array}{l}\text { Referência clara ao nome do } \\
\text { alimento alergênico. }\end{array}$ \\
\hline Estados Unidos & $\begin{array}{l}\text { 1. Imediatamente após ou } \\
\text { adjacente à lista de } \\
\text { ingredientes; ou } \\
\text { 2. Na lista de ingredientes. }\end{array}$ & $\begin{array}{l}\text { 1. Fonte do tamanho ou } \\
\text { maior que da lista de } \\
\text { ingredientes. } \\
\text { 2. Entre parênteses, quando } \\
\text { o ingrediente for um } \\
\text { derivado do alimento } \\
\text { alergênico. }\end{array}$ & $\begin{array}{l}\text { 1. Expressão "contém" seguida } \\
\text { pelo nome comum do alimento } \\
\text { alergênico de origem do } \\
\text { alérgeno. } \\
\text { 2. Nome comum do alimento } \\
\text { alergênico de origem do } \\
\text { alérgeno. }\end{array}$ \\
\hline $\begin{array}{l}\text { Austrália Nova } \\
\text { Zelândia }\end{array}$ & $\mathrm{Na}$ lista de ingredientes. & Não especificado. & Não especificado. \\
\hline
\end{tabular}

Fonte: Autores (com base em Fda, 2004; Australia New Zealand Food Standards Code, 2011; European Parliament, 2011; Brasil, 2015 A; Argentina, 2017; República del Paraguay, 2018).

O termo “ALÉRGICOS” anteposto à declaração dos alergênicos foi instituído pela ANVISA na RDC nº 26/2015 para direcionar a informação ao grupo de pessoas de interesse. Dessa maneira, evita-se que indivíduos sem alergias alimentares interpretem a declaração de forma incorreta (Brasil, 2017 a).

\subsubsection{Declaração preventiva de alergênicos por risco de contaminação cruzada}

A rotulagem de alergênicos pode ser dividida em duas categorias: a declaração de alimentos que fazem parte da composição do produto como ingrediente ou aditivo alimentar, e a declaração de alergênicos que podem estar presentes no alimento devido à contaminação cruzada. Embora a declaração preventiva tenha como objetivo informar um risco potencial ao consumidor alérgico, ela é controversa. Isto porque pode ser utilizada pelos fabricantes como uma alternativa a falta de controle da contaminação cruzada e ausência de um Programa de Controle de Alergênicos (PCAL) e, dessa forma, não 
representar um risco real de contaminação dentro dos padrões de BPF, mas sim a negligência por parte dos fabricantes (Allen et al., 2014).

A disseminação de declarações preventivas e a não padronização das advertências utilizadas podem causar dúvidas entre os consumidores e contribuir para que elas sejam desconsideradas (Allen et al., 2014), além de restringirem o acesso de indivíduos alérgicos aos alimentos. Ao analisar a rotulagem de produtos do mercado americano, Pieretti et al. (2009) encontraram uma prevalência de $17 \%$ de declarações preventivas em um total de 20.241 alimentos. As categorias em que as advertências foram mais comuns incluíram chocolates (54\%), biscoitos (53\%), misturas prontas para bolos (40\%) e misturas prontas para panquecas (32\%). Tais autores identificaram vinte e cinco modelos diferentes de advertências, sendo que as mais comuns foram "Pode Conter" (21\%), "Pode Conter Traços" (13\%) e "Fabricado Nas Mesmas Instalações Onde São Processados" (13\%). Numa pesquisa realizada na Austrália, foi evidenciada uma prevalência ainda maior, $65 \%$ de 1.355 produtos continham declarações sobre a presença não intencional de alergênicos. A expressão mais utilizada neste caso foi "Pode Conter Traços" (Zurzolo et al., 2013). Em ambos os estudos, castanhas e amendoim foram identificados como os principais alimentos declarados preventivamente.

Uma avaliação da presença de alergênicos em produtos alimentícios embalados, no Reino Unido, no período de julho de 2012 a maio de 2013, demonstrou que o nível de contaminação cruzada não corresponde à presença de declaração preventiva nos alimentos estudados. Muitas amostras com advertência de contaminação cruzada não apresentaram níveis detectáveis dos alergênicos correspondentes, neste caso amendoim, nozes e leite. O amendoim estava ausente em $45 \%$ das amostras em que foi declarado, nozes em $44 \%$ e o leite em $18 \%$. Ao passo em que 2,1\% das amostras positivas para a presença de leite não apresentavam advertência de contaminação cruzada (Hirst, 2014).

$\mathrm{Na}$ Irlanda, um estudo de monitoramento semelhante foi divulgado com os resultados da análise de 214 produtos para a presença de amendoim, ovo e soja. Entre os 106 que não apresentavam advertência de contaminação cruzada, detectou-se a presença de pelo menos um desses alergênicos em $11 \%$ das amostras. Já entre os produtos contendo a advertência preventiva na rotulagem, apenas sete de um total de 108 produtos, ou seja, 6,5\% obtiveram resultado positivo para o alergênico declarado (Food Safety Authority of Ireland, 2011).

A ANVISA, por meio da RDC n $26 / 2015$, declara que "nos casos em que não for possível garantir a ausência de contaminação cruzada dos alimentos, ingredientes, aditivos alimentares ou coadjuvantes de tecnologia por alérgenos alimentares, deve constar no rótulo a declaração "Alérgicos: Pode Conter (nomes comuns dos alimentos que causam alergias alimentares)". Entretanto, a utilização da declaração "Pode Conter" deve ser baseada em um PCAL (Brasil, 2015 a).

\subsubsection{Alegação de ausência de alergênicos}

A alegação de ausência de alergênicos pelo uso de expressões como "Não Contém" e "Livre De" não foi regulamentada pelos países incluídos no estudo de Gendel (2012). Segundo Barnett et al. (2011), indivíduos alérgicos, sobretudo aqueles que já sofreram reações alérgicas severas, apontaram a alegação de ausência de castanhas como uma possível melhoria para a rotulagem de alergênicos. Contudo, este tipo de declaração foi proibido no Brasil, uma vez que a ANVISA não teve condições de estabelecer critérios capazes de proteger os consumidores sensíveis. A Agência reconheceu o potencial deste tipo de alegação para uma escolha mais conveniente entre os consumidores alérgicos, mas destaca a dificuldade de estabelecer limites seguros a todos os indivíduos com alergias alimentares e as limitações dos métodos analíticos disponíveis para assegurar a ausência de constituintes alergênicos (Brasil, 2017 a).

\subsubsection{Programas de controle e avaliação do risco de contaminação cruzada}

O PCAL representa uma ferramenta de gestão aplicável a todas as empresas que atuam na cadeia produtiva de 
alimentos, a qual permite a identificação e o controle de substâncias alergênicas, prevenindo a contaminação cruzada do produto final por alérgenos. Ele deve ser implementado em conjunto com as BPF e o Sistema de Análise de Perigos e Pontos Críticos de Controle (APPCC). Desta forma, o PCAL deve ser devidamente documentado e monitorado sistematicamente.

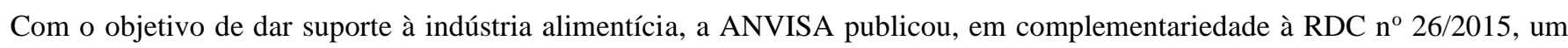
Guia sobre PCAL. Neste contexto, sete fatores podem ser destacados pelas suas relevâncias na identificação das etapas críticas para controle do risco de contaminação cruzada na cadeia de produção: i) matérias primas e ingredientes; ii) processo produtivo; iii) funcionários e colaboradores; iv) higienização; v) embalagem; vi) armazenamento; e vii) transporte (Brasil, 2018).

As matérias-primas representam um potencial fonte de contaminação por alérgenos alimentares nos alimentos processados. Esses alérgenos podem estar intencionalmente presentes nos ingredientes ou insumos utilizados na produção, ou serem resultado de uma contaminação cruzada durante o transporte ou manipulação do material. Diante deste cenário, o Guia sobre PCAL alerta os fabricantes para a importância de se ter procedimentos para a gestão de fornecedores, visando a garantia de aquisição de matérias-primas de empresas que possuam um sistema eficiente para o controle de alergênicos, avaliando os fornecedores por meio de auditorias, ou questionários, e verificando se as especificações técnicas e informações sobre a composição dos produtos estão completas e adequadas. Além disso, é recomendada atenção para troca de fornecedores ou alterações na matéria-prima de um mesmo fornecedor. Durante o recebimento dos ingredientes e matérias-primas, é destacada a necessidade de avaliação da conformidade em relação às especificações exigidas, além da garantia de que os produtos continuem sob estas condições durante o tempo de armazenamento pré-produção. Durante a produção, deve haver o cuidado com o reprocessamento de produtos contendo alérgenos, por exemplo, os óleos utilizados para a fritura de alimentos que contenham substâncias alergênicas em sua composição devem ser reutilizados apenas para produtos que também contenham intencionalmente esse ingrediente (Brasil, 2018).

A ANVISA afirma que a melhor medida para a prevenção de contaminação cruzada consiste na produção de alimentos contendo alergênicos em espaços físicos, ou linha de produção, separados daqueles que não contém adição intencional de alergênicos. Nos casos em que esta separação não é possível por motivos ligados a características das empresas, a agência preconiza o uso de barreiras técnicas e medidas suplementares para evitar a contaminação cruzada, incluindo: i) cuidados com a ordem de produção, começando pelos produtos com menor quantidade ou nenhum alergênico, seguindo para os com maior número de ingredientes alergênicos; ii) higienização adequada dos equipamentos e utensílios; iii) uso de barreiras físicas para a contenção do alérgenos, principalmente quando utilizam-se insumos em pó, ou circuitos fechados; iv) emprego de sistema de ventilação que não favoreça a dispersão de partículas, evitando-se correntes de ar sobre o local de manipulação; v) sistema de climatização com renovação adequada do ar e filtros com capacidade de retenção de partículas; vi) sistema de pressão positiva para evitar a entrada de ar contaminado nas áreas livres; vii) limpeza adequada de superfícies planas para evitar a deposição de sustâncias alergênicas; viii) técnicas de limpeza que evitem a dispersão de partículas; ix) controle da movimentação de matérias-primas dentro da fábrica; x) processamento de alimentos alergênicos prioritariamente em área separada, ou posterior o processamento de outros ingredientes, seguido por higienização adequada; e xi) quando possível, utilização de equipamentos e utensílios distintos para alimentos alergênicos, devidamente identificados (Brasil, 2018).

Outros pontos importantes abordados pelo Guia foram a capacitação e treinamento dos funcionários e colaboradores, o cuidado para que as embalagens sejam destinadas ao produto correto, evitando-se erros na informação fornecida ao consumidor, e medidas para o armazenamento e transporte de produtos acabados para que estes não sejam contaminados por alérgenos após sua produção (Brasil, 2018).

O monitoramento das medidas de controle estabelecidas pelo PCAL é imprescindível para identificar falhas, 
estabelecer possíveis medidas corretivas e assim garantir sua correta execução. Além disso, o PCAL deve ser revisado sempre que houver alterações no processo produtivo, inclusão de novos produtos no portfólio da empresa, alteração na formulação dos produtos, solicitação pela equipe técnica responsável ou autoridades sanitárias e relatos de consumidores sobre reações alérgicas relacionadas ao consumo de alimentos fabricados pela empresa (Brasil, 2018).

A validação do PCAL pela utilização de métodos analíticos que comprovem se as medidas adotadas foram suficientes ou não para evitar a contaminação cruzada por alimentos alergênicos é, até o momento, opcional. Ou seja, a necessidade de realização ou não desta etapa fica a critério da empresa. A ANVISA, contudo, faz uma ressalva a respeito da escolha da metodologia, que deve levar em consideração o limite de detecção do método, uma vez que pequenas quantidades de substâncias alergênicas podem desencadear respostas alérgicas. A utilização de advertência de contaminação cruzada, conforme os critérios da RDC no 26 de 2015 e as recomendações do Guia sobre PCAL, deve, portanto, ser uma decisão da indústria, baseada no PCAL implementado (Brasil, 2018).

Na Austrália e Nova Zelândia, indústrias de alimentos associadas desenvolveram uma metodologia para a avaliação do risco de contaminação cruzada por alimentos alergênicos chamada Voluntary Incidental Trace Allergen Labelling (VITAL) que atualmente está na terceira versão VITAL 3.0, sob responsabilidade do Allergen Bureau (Zurzolo et al., 2016). Apesar de possuir o mesmo objetivo do PCAL no Brasil, o VITAL 3.0 possui uma abordagem quantitativa para determinar quando a declaração preventiva é adequada. Foram estabelecidas, com base na literatura disponível, doses de referência das proteínas alergênicas que representam um risco de reação alérgica para apenas a parcela mais sensível da população alérgica (entre 1\% e 5\%). A junção dessas informações às porções usuais de cada alimento possibilitou o cálculo das quantidades máximas permitidas de alérgenos nos produtos finais. Foram estabelecidos, portanto, dois níveis de ação. No primeiro nível de ação a rotulagem de contaminação cruzada não é necessária, enquanto no segundo nível a declaração de contaminação cruzada, "PODE ESTAR PRESENTE”, deve ser utilizada, seguindo a padronização do VITAL 3.0 (Allergen Bureau, 2020).

A tomada de decisão em relação ao nível de ação para cada produto é baseada no cálculo da concentração final de proteínas alergênicas por porção do alimento. Os pontos críticos de contaminação cruzada na cadeia produtiva e os ingredientes utilizados são avaliados (Allergen Bureau, 2020).

De acordo com o VITAL, quando o alergênico pode estar presente em algum ingrediente na forma de partículas, por exemplo, uma semente de gergelim, a declaração de contaminação cruzada deve ser realizada independentemente da concentração de proteínas por porção. Quando o alergênico pode ser disperso uniformemente no alimento, deve-se estimar a concentração de proteínas no produto final a partir da concentração no ingrediente e da quantidade utilizada na fabricação (Allergen Bureau, 2020).

No processo produtivo os pontos onde contaminação cruzada for provável devem ser identificados e avaliados quanto à possibilidade de redução ou eliminação dos riscos. Caso não seja possível a eliminação da contaminação cruzada, deve-se estimar a contribuição de cada ponto para a concentração final de alérgenos no alimento (Allergen Bureau, 2020).

Infelizmente, para a maioria dos países, o emprego de um PCAL não é regulamentado nas respectivas legislações, de forma que avaliações de risco formais não vêm sendo realizadas para a declaração de potencial contaminação não intencional por alimentos alergênicos.

\section{Considerações Finais}

A alergia alimentar é um tema importante para a saúde pública e, atualmente, como consequência da regulamentação da rotulagem obrigatória de alimentos alergênicos, encontra-se em evidência no Brasil. O panorama mundial também não é diferente, uma vez que várias questões ainda necessitam de respostas, tanto relacionadas aos aspectos clínicos, como etiologia, epidemiologia, tratamento e diagnóstico; quanto aos assuntos regulatórios, envolvendo o processamento e a informação aos 
consumidores sobre a presença de alimentos alergênicos.

A presente revisão permitiu evidenciar a evolução na regulamentação do tema, com perspectivas de que a mesma atinja não somente alimentos pré-embalados, mas também aqueles não embalados ou comercializados a granel e os serviços de alimentação. Outro aspecto observado como de extrema relevância foi a diversidade nas legislações de diferentes países, tanto em relação aos alimentos alergênicos que devem ser declarados, como nas formas de comunicação com os consumidores, e também na necessidade de implementação de PCAL. No atual cenário de globalização e aniquilação do espaço pelo tempo, apontamos para a necessidade de convergência das regulamentações dos diferentes países para uma harmonização, sob coordenação do Codex Alimentarius, visando à promoção da segurança dos alimentos e do comércio internacional, com impactos na saúde da população mundial.

Trabalhos futuros abordando as aplicações e limitações de diferentes técnicas analíticas para a efetiva implementação dos instrumentos legais relacionados aos alimentos alergênicos são necessários, com enfoque nos principais desafios e tendências.

\section{Colaboradores}

MPP Palhares: Concepção; Investigação; Compilação dos dados; Redação, revisão e edição do manuscrito. SVC Souza: Concepção e delineamento; Revisão crítica, edição e aprovação da versão final; Supervisão e administração do projeto de pesquisa. Santos, Santos e Goddard: Redação, revisão e edição do manuscrito.

\section{Referências}

Agência Nacional de Vigilância Sanitária (ANVISA). (2002). Resolução RDC $n^{\circ} 259$, de 20 de setembro de 2002 . Regulamento Técnico sobre Rotulagem de Alimentos Embalados. Brasília, DF.

Agência Nacional de Vigilância Sanitária (ANVISA). (2015a). Resolução $R D C n^{\circ}$ 26, de 02 de julho de 2015. Dispõe sobre os requisitos para rotulagem obrigatória dos principais alimentos que causam alergias alimentares. Brasília, DF.

Agência Nacional de Vigilância Sanitária (ANVISA). (2015b). Relatório de Análise de Contribuições em Consulta Pública e Audiência Pública. http://antigo.anvisa.gov.br/documents/33880/2552856/Relat\%C3\%B3rio+de+An\%C3\%A1lise+de+Contribui\%C3\%A7\%C3\%B5es+da+CP+29-2014/ca bfa4dc-440b-4841-a713-10e8ddd77838.

Agência Nacional de Vigilância Sanitária (ANVISA). (2017 a). Perguntas e Respostas sobre Rotulagem de Alimentos Alergênicos. (5a ed.), Brasília. 2017. https://www.gov.br/anvisa/pt-br/centraisdeconteudo/publicacoes/alimentos/perguntas-e-respostas/rotulagem-de-alergenicos.pdf.

Agência Nacional de Vigilância Sanitária (ANVISA). (2017 b). Resolução RDC $n^{\circ} 136$, de 08 de fevereiro de 2017 . Estabelece os requisitos para declaraçãoobrigatória da presença de lactose nos rótulosdos alimentos. Brasília, DF.

Agência Nacional de Vigilância Sanitária (ANVISA). (2018). Guia sobre Programa de Controle de Alergênicos. Guia n 05/2018 - Versão 2. 2018. http://antigo.anvisa.gov.br/documents/10181/2779039/\%281\%29Guia+Programa+Controle+de+Alergenicos+versao+2.pdf/69af35f5-cc11-412e-ade5$4 \mathrm{~d} 47 \mathrm{fef} 14 \mathrm{f} 5 \mathrm{e}$.

Agência Nacional de Vigilância Sanitária (ANVISA). (2019). Guia para Comprovação da Segurança de Alimentos e Ingredientes. http://antigo.anvisa.gov.br/documents/10181/5355698/Guia+Seguran\%C3\%A7a+de+Alimentos.pdf/dae93caa-7418-4b9a-97f2-2ec9ebc139e2

Aiking, H., Boer, J. (2020). The next protein transition. Trends in Food Science \& Technology, 105, 515-522.

Allen, K. J., et al. (2014). Precautionary labelling of foods for allergen content: are we ready for a global framework? World Allergy Organization Journal, 7(10), 1-14.

Allergen Bureau. (2020). Food Industry Guide to the Voluntary Incidental Trace Allergen Labelling (VITAL) Program Version 3.0. Austrália e Nova Zelândia. October 2012. http://allergenbureau.net/wp-content/uploads/2020/10/Food_Industry_Guide_VITAL_Program_Version_October_2020_VF1.pdf

ASBAI. Associação Brasileira de Alergia e Imunopatologia. (2018). Consenso Brasileiro sobre Alergia Alimentar: Parte 1 - Etiopatogenia, clínica e diagnóstico. Arquivos de Asma Alergia e Imunologia, 2(1).

Australia New Zealand Food Standards Code. (2011). Standard 1.2.3 - Mandatory Warning and Advisory Statements and Declarations. https://www.legislation.gov.au/Details/F2011C00610.

Barnett, J., et al. (2011). How do peanut and nut-allergic consumers use information on the packaging to avoid allergens? Allergy, 66, $969-978$.

Bernardo, F. (2006). Perigos sanitários nos alimentos. Revista Segurança e Qualidade Alimentar, 1, 3-7. 
Research, Society and Development, v. 10, n. 1, e7310111541, 2021

(CC BY 4.0) | ISSN 2525-3409 | DOI: http://dx.doi.org/10.33448/rsd-v10i1.11541

Besler, M. Determination of allergens in foods. TrAC Trends in Analytical Chemistry, 20(11), 662-672.

Boyce, J. A., et al. Guidelines for the diagnosis and management of food allergy in the United States: Summary of the NIAID- Sponsored Expert Panel Report. Nutrition, 27(2), 253-267.

Brandtzaeg, P. Food allergy: separating the science from the mythology. Nature Reviews Gastroenterology and Hepatology, 7(7), 380-400.

Codex Alimentarius Commission. (1993). Report of the Twenty-Second Session of the Codex Committee on Food Labelling. http://www.fao.org/fao-whocodexalimentarius/meetings-reports/en/?y=1993\&s=1991.

Codex Alimentarius Commission. (2018). Report of The Forty-Fourth Session of The Codex Committee On Food Labelling. http://www.fao.org/fao-whocodexalimentarius/sh-proxy/en/?lnk=1\&url=https\%253A\%252F\%252Fworkspace.fao.org\%252Fsites\%252Fcodex\%252FMeetings\%252FCX-714-

44\%252FREPORT\%252FREP18_FLe.pdf.

Codex Alimentarius Commission. (2019). Discussion Paper on Allergen Labelling http://www.fao.org/fao-who-codexalimentarius/shproxy/en/?lnk=1\&url=https\%253A\%252F\%252Fworkspace.fao.org\%252Fsites\%252Fcodex\%252FMeetings\%252FCX-714-

45\%252Fdocuments\%252Ffl45_08e.pdf

Codex Alimentarius. (2001). Codex Alimentarius - Food Labeling - Complete Texts - Revised 2001. http://www.fao.org/docrep/005/Y2770E/ y2770e00.htm\#Contents.

European Parliament. (2003). Directive 2003/89/EC of the European Parliament and of the Council of 10 November 2003. Amending Directive 2000/13/EC as regards indication of the ingredients present in foodstuffs. Official Journal of the European Union. http://eurlex.europa.eu/LexUriServ/LexUriServ.do?uri=OJ:L: 2003:308:0015:0018:EN:PDF

European Parliament. (2006). Commission Directive 2006/142/EC of 22 December 2006. Amending Annex IIIa of Directive 2000/13/EC of the European Parliament and of the Council listing the ingredients which must under all circumstances appear on the labelling of foodstuffs. Official Journal of the European Union. https://eur-lex.europa.eu/legal-content/EN/TXT/PDF/?uri=OJ:L:2006:368:FULL\&from=PT

European Parliament. (2007). Commission Directive 2007/68/EC of 27 November 2007. Amending Annex IIIa to Directive 2000/13/EC of the European Parliament and of the Council as regards certain food ingredients. Official Journal of the European Union. https://eur-lex.europa.eu/legalcontent/EN/TXT/PDF/?uri=CELEX:32007L0068\&from=EN

European Parliament. (2011). Regulation (Eu) No 1169/2011 of the European Parliament and of the Council of 25 October 2011. On the provision of food information to consumers, amending Regulations (EC) No 1924/2006 and (EC) No 1925/2006 of the European Parliament and of the Council, and repealing Commission Directive 87/250/EEC, Council Directive 90/496/EEC, Commission Directive 1999/10/EC, Directive 2000/13/EC of the European Parliament and of the Council, Commission Directives 2002/67/EC and 2008/5/EC and Commission Regulation (EC) No 608/2004. http://eur-lex.europa.eu/legalcontent/EN/TXT/PDF/?uri=CELEX:32011R1169\&from=EN

Fda - Food and Drug Administration. (1996). Allergens - Label Declaration of Allergenic Substances in Foods; Notice to Manufacturers. 1996. http://www.fda.gov/food/guidanceregulation/

Fda - Food and Drug Administration. (2001). Compliance Policy Guide Sec. 555.250 Statement of Policy for Labeling and Preventing Cross-contact of Common Food Allergens. 2001. http://www.fda.gov/ICECI/ComplianceManuals/CompliancePolicyGuidanceManual/ucm074552.htm

Fda - Food and Drug Administration. (2004). Food Allergen Labeling and Consumer Protection Act of 2004. https://www.fda.gov/media/77570/download

Fda - Food and Drug Administration. (2020 a). Inventory of Notifications Received under 21 U.S.C. 343(w)(7) for Exemptions from Food Allergen Labeling. Online. https://www.fda.gov/food/food-labeling-nutrition/inventory-notifications-received-under-21-usc-343w7-exemptions-food-allergen-labeling

Fda - Food and Drug Administration. (2020 b). Inventory of Petitions Received under 21 U.S.C. 343(w)(6) for Exemptions from Food Allergen Labeling. Online. https://www.fda.gov/food/food-labeling-nutrition/inventory-petitions-received-under-21-usc-343w6-exemptions-food-allergen-labeling

Food Safety Authority of Ireland. (2011). Food Allergens \& Labelling Survey June 2011. https://www.fsai.ie/resources.../allergen_labelling_2011.html.html

Fsa - Food Standards Agency. (2015). Allergy: what to consider when labelling food. Reino Unido. 2015. https://www.food.gov.uk/sites/default/files/multimedia/pdfs/publication/allergy-labelling-prepacked.pdf.

Gendel, S. M. (2012). Comparison of international food allergen labeling regulations. Regulatory Toxicology and Pharmacology, 63(2), 279-285.

Gendel, S. M. (2013). The Regulatory Challenge of Food Allergens. Journal of Agricultural Food Chemistry, 61, 5634-5637.

Grimshaw, K. E. C., et al. (2014). Diet and food allergy development during infancy: Birth cohort study findings using prospective food diary data. Allergy, 133(2), 511-519.

Haddeland, U., et al. (2005). Putative regulatory T cells are impaired in cord blood from neonates with hereditary allergy risk. Pedriatr Allergy Immunol., 16, 104-112.

Hirst, B. (2014). Survey of Allergen Advisory Labelling and Allergen Content of UK Retail Pre-Packed Processed Foods. Reading Scientific Services Ltd. https://www.food.gov.uk/science/research/allergy-research/fs241038.

Jackson, W. F. (2003). Food Alergy. 2003. http://ilsi.eu/wp-content/uploads/sites/3/2016/06/C2003Food_All.pdf.

Jones, S. M., Burks, A. W., \& Dupont, C. (2014). tate of the art on food allergen immunotherapy: Oral, sublingual, and epicutaneous. American Academy of Allergy, Asthma \& Immunology. 2014. http://dx.doi.org/10.1016/j.jaci.2013.12. 
Lanser, B. J., Wright, B. L., Orgel, K. A., Vickery, B. P., \& Fleischer, D. M. (2015). Current Options for the Treatment of Food Allergy. Pediatr Clin., 62, $1531-1549$

Lee, B. W., Pei-Chi Shek, L., Gerez, I. F. A., Soh, S. E., \& Van Bever, H. P. (2008). Food Allergy - Lessons from Asia. World Allergy Organ J., 1(7), 129133.

Marins, B. R., Araujo, I. S., \& Jacob, S. C. (2014). Vigilância Sanitária e direito à comunicação: a rotulagem de alimentos como espaço de cidadania. Vig Sanit Debate, 2(4), 86-95.

Martino, D. J., \& Prescott, S. L. (2010). Silent mysteries: epigenetic paradigms could hold the key to conquering the epidemic of allergy and immune disease. Allergy, 65, 7-15.

Mcbride, D., et al. (2012). The EuroPrevall birth cohort study on food allergy: baseline characteristics of 12,000 newborns and their families from nine European countries. Pediatr Allergy Immunol, 23, 230-239.

Mercosul (2015 a). Mercosur/SGT No 3/Acta № 04/15 LVII Reunión Ordinaria del Subgrupo de Trabajo № 3 "Reglamentos Técnicos y Evaluación de La Conformidad". http://www.puntofocal.gov.ar/doc/lvii_ac_04-15_acta.pdf

Mercosul (2015 b). Mercosur/GMC/Acta No 02/15 XLVI Reunión Extraordinaria Del Grupo Mercado Común. http://www.puntofocal.gov.ar/doc/gmc_ex0215.pdf

Ministério da Saúde. Secretaria de Atenção à Saúde. Departamento de Atenção Básica. (2014). Guia alimentar para a população brasileira. (2a ed.), 1. reimpr. Brasília: Ministério da Saúde, 156 p.

Ministerio de la Salud Pública y Bienertar Social. (2018). Resolución S.G. $n^{\circ}$ 402. https://www.inan.gov.py/site/?p=1212

Neu, J., \& Rushing, J. (2011). Cesarean Versus Vaginal Delivery: Long-term Infant Outcomes and the Hygiene Hypothesis. Clinics in perinatology, 38(2), $321-331$.

Odijk, J., et al. (2003). Breastfeeding and allergic disease: a multidisciplinary review of the literature (1966-2001) on the mode of early feeding in infancy and its impact on later atopic manifestations. Allergy, 58, 833-843.

Pereira A. S. et al. (2018). Metodologia da pesquisa científica. [e-book]. Santa Maria. Ed. UAB/NTE/UFSM. https://repositorio.ufsm.br/bitstream/handle/1/15824/Lic_Computacao_Metodologia-Pesquisa-Cientifica.pdf?sequence=1.

Pieretti, M. M., et al. (2009). Audit of manufactured products: Use of allergen advisorylabels and identification of labeling ambiguities. $J$ Allergy Clin Immunol., 124(2), 337-341.

República Oriental del Uruguay (2020). Proyecto para declaración de alérgenos y sustancias que producen reacciones adversas en los rótulos de los alimentos, cualquiera sea su origen, envasados en ausencia del cliente, listos para ser ofrecidos al consumidor (dec. 117/006 del RBN). https://www.gub.uy/ministeriosalud-publica/sites/ministerio-salud-publica/files/2020-09/PROYECTO\%20DE\%20AL\%C3\%89RGENOS\%20Y\%20SUSTANCIAS\%20ADVERSAS\%20P ARA\%20CONSULTA\%20P\%C3\%9ABLICA.pdf.

Santos, A. L. S. $\beta$-lactoglobulina em biscoitos semidoces: estudo de degradação no processamento e potencial antigênico, validação de método e avaliação da rotulagem. [Dissertação de Mestrado do Programa de Pós-graduação em Ciência de Alimentos da Universidade Federal de Minas Gerais]. Belo Horizonte: UFMG. https://repositorio.ufmg.br/handle/1843/BUBD-AMUSAB.

Santos, P. P. B. Estudo da degradação e potencial antigênico de proteínas do ovo no processamento de biscoitos semidoces e validação de método imunoenzimático. [Dissertação de Mestrado do Programa de Pós-graduação em Ciência de Alimentos da Universidade Federal de Minas Gerais]. Belo Horizonte: UFMG. https://repositorio.ufmg.br/handle/1843/BUOS-BATFN3

Secretaría de Políticas, Regulación e Institutos, Secretaría De Agregado De Valor. (2017). Resolución Conjunta 11-E/2017. https://www.argentina.gob.ar/normativa/nacional/resoluci\%C3\%B3n-11-2017-280582/texto

Sicherer, S. H. (2011). Epidemiology of food allergy. The Journal of Allergy and Clinical Immunology, 127(3), 594-602.

Sicherer, S. H., Sampson, H. A. (2018). Food allergy: A review and update on epidemiology, pathogenesis, diagnosis, prevention, and management. The Journal of Allergy and Clinical Immunology, 141(1), 45-58.

Solé, D., et al. (2008). Consenso Brasileiro sobre alergia alimentar: 2007. Revista Brasileira de Alergia e Imunopatologia, 31(2), 64-89.

Zurzolo, G. A., et al. (2013). Precautionary allergen labelling following new labelling practice in Australia. Journal of Paediatrics and Child Health, 49, E306-E310.

Zurzolo, G. A., et al. (2016). Is advising food allergic patients to avoid food with precautionary allergen labelling out of date? Curr Opin Allergy Clin Immunol., 16(3), 272-277. 